\title{
Application of SAFT-VRE in the Flowsheet Simulation of an Advanced PUREX Process
}

DOI:

10.1021/acs.iecr.8b05606

\section{Document Version}

Accepted author manuscript

Link to publication record in Manchester Research Explorer

\section{Citation for published version (APA):}

Chen, H., Masters, A. J., Taylor, R. J., Jobson, M., \& Woodhead, D. A. (2019). Application of SAFT-VRE in the Flowsheet Simulation of an Advanced PUREX Process. Industrial \& Engineering Chemistry Research.

https://doi.org/10.1021/acs.iecr.8b05606

\section{Published in:}

Industrial \& Engineering Chemistry Research

\section{Citing this paper}

Please note that where the full-text provided on Manchester Research Explorer is the Author Accepted Manuscript or Proof version this may differ from the final Published version. If citing, it is advised that you check and use the publisher's definitive version.

\section{General rights}

Copyright and moral rights for the publications made accessible in the Research Explorer are retained by the authors and/or other copyright owners and it is a condition of accessing publications that users recognise and abide by the legal requirements associated with these rights.

\section{Takedown policy}

If you believe that this document breaches copyright please refer to the University of Manchester's Takedown Procedures [http://man.ac.uk/04Y6Bo] or contact uml.scholarlycommunications@manchester.ac.uk providing relevant details, so we can investigate your claim.

\section{OPEN ACCESS}




\section{Application of SAFT-VRE in the Flowsheet}

\section{Simulation of an Advanced PUREX Process}

Hongyan Chen ${ }^{* 1}$, Andrew J. Masters ${ }^{1}$, Robin Taylor ${ }^{2}$, Megan Jobson ${ }^{1}$, David Woodhead ${ }^{2}$

${ }^{1}$ School of Chemical Engineering and Analytical Science, Oxford Road, University of Manchester, Manchester, M13 9PL, UK

${ }^{2}$ National Nuclear Laboratory, Central Laboratory, Sellafield, Seascale, Cumbria, CA20 1PG, UK

KEYWORDS: SAFT-VRE, uranium, nitric acid, activity coefficients, density

ABSTRACT: SAFT-VRE is an extension of the statistical associating fluid theory for potentials of variable range (SAFT-VR) that can be used to describe the thermodynamic properties of strong-electrolyte solutions. Here the SAFT-VRE method is used in a flowsheet simulation code to calculate the densities of uranyl-nitric acid aqueous solutions and the activities of species that are needed for the calculation of the distribution coefficients of nitric acid and uranium in the nitric acid - $30 \%$ tributyl phosphate (TBP) extraction system that is used in an advanced PUREX process for the reprocessing of spent nuclear fuels. Simulation results of both single stage extraction experiments and of a multistage flowsheet test showed

*Corresponding author, email: Hongyan.chen@manchester.ac.uk 
that the SAFT-VRE method can be used in flowsheet simulations with a reasonable accuracy, thus demonstrating for the first time that thermodynamically based meso-scale SAFT-VRE models can be linked to the macro-scale model of the PUREX solvent extraction process.

\section{INTRODUCTION}

In the management and disposal of spent nuclear fuel from nuclear power production, the presence of long-lived, heat generating and radiotoxic actinides complicate storage in a geological disposal facility. Of particular concern on a timescale of millions of years, neptunium-237 with a half-life of about 2 million years is potentially mobile in the environment under certain conditions. ${ }^{1}$ Therefore, removing actinides, including neptunium, from spent nuclear fuel can significantly reduce the long-term radioactivity of the waste and can potentially increase public acceptance for the disposal facility. ${ }^{2-5}$

The standard industrial method for reprocessing spent nuclear fuel is the PUREX process. ${ }^{6,7}$ This technology is based on solvent extraction between aqueous nitric acid and tributyl phosphate (TBP) diluted into an organic kerosene phase. One option is to adapt this process to recover and recycle neptunium for incorporation in new fuel for burning in nuclear reactors including thermal and fast reactors such as the liquid metal fast breeder reactor (LMFBR) and the minor actinide burner $(\mathrm{MAB}) .^{2}$ The conventional PUREX process, however, does not efficiently recover neptunium and current reprocessing plants tend to split neptunium between several products that then require specific stages to purify the products from neptunium contamination. Improved control of neptunium is considered to be an essential feature of an “advanced PUREX" process. ${ }^{7,11}$ In consequence, significant efforts have been made to modify and simplify the PUREX process so that it efficiently extracts neptunium along with uranium and plutonium. ${ }^{8-10}$ 
However, due to the significant differences in extractability of the various neptunium oxidation states and the sensitivities of the neptunium redox reactions to nitric acid and nitrous acid, ${ }^{11-13}$ it is not easy to fully route neptunium to a single desired process stream. ${ }^{9,10}$ Hence, accurate models of the solvent extraction process are needed for predicting neptunium extraction behaviour, to guide experimental design and to find operating conditions that facilitate complete neptunium recovery.

Thermodynamic and physical properties, such as the equilibrium distribution of species and liquid mixture densities are critical data for modelling solvent extraction processes. Due to the complexity of the composition of reprocessing solutions and the non-ideal behaviour of the electrolyte solution in the process, normal thermodynamic methods developed for nonelectrolyte system, such as equation of states, Wilson and NRTL methods, ${ }^{14}$ cannot easily be used to describe the thermodynamic properties of this system. Empirical distribution coefficient models, therefore, have been used in many solvent extraction flowsheet simulations. $^{15-19}$

This was, in fact, the approach used in our previous work $^{20,21}$ on the development of a flowsheet simulation code for the advanced PUREX process; the approach was validated using data obtained from experimental trials ${ }^{10}$ on single and multi-stage centrifugal contactors. In particular, our model developed based on the Jobin's distribution coefficient model ${ }^{16,17}$ which was used in the established and open source SEPHIS code ${ }^{16}$ was shown to be in reasonable agreement with a compilation of the published experimental data. ${ }^{22}$ However, process level models built on a more robust theoretical basis using new meso-scale methods could offer potential improvements in solvent extraction modelling capability. This work investigates such a modelling approach. 
Statistical Associating Fluid Theory (SAFT) ${ }^{23}$ is an advanced thermodynamic theory based on firm statistical mechanical principles. Essentially it employs a perturbation approach about a reference hard sphere fluid and thereby incorporates the effects of attractive interactions, chain formation and association, such as hydrogen bonded interactions. The parameters required are closely related to molecular geometry and the form of the inter-molecular pair potentials of interaction. They thus carry physical meaning rather than merely being fitting parameters. The aim, therefore, is to explore whether this approach could be more robust than semi-empirical methods and whether SAFT-based models can accurately describe many relevant properties of pure components and mixtures, using experimental data for validation purposes.

SAFT is becoming more established, and while there are variations of detail, the basic approach is common to all SAFT models. We give a non-exhaustive set of references to several of these techniques. ${ }^{24-31}$ These theories promise to give extremely accurate predictions. ${ }^{31-33}$ In this paper, however, our aim is not so much to find the most accurate available models, but rather to show how such theories may be incorporated into the flowsheet modelling for extraction processes.

SAFT-VRE $^{27}$ is an extension of SAFT-VR ${ }^{25}$ that can model the thermodynamic behaviour of strong electrolyte solutions. SAFT-VRE has been used to predict the phase equilibria and thermodynamic properties of electrolyte solutions. ${ }^{34-36}$ In this paper, we explore the use of SAFT-VRE to calculate activity coefficients of uranium and nitric acid in aqueous solution, in the context of an advanced PUREX process. These activity coefficients are then used to construct models for distribution coefficients and the density of the aqueous phase for application in flowsheet simulations. 


\section{BACKGROUND}

\subsection{SAFT-VRE model}

In the SAFT-VRE model of aqueous electrolytes, a water molecule is modelled as a hard sphere of diameter $\sigma_{11}$ with four short-range attractive sites for association. The sites are situated off-centre at a distance $r_{d 1}$. When a donor site and an acceptor site are closer than a distance $r_{c 1}$, they interact with an attractive energy $\varepsilon_{11}^{\mathrm{HB}}$. The four sites represent the two hydrogens and two oxygen lone pairs of electrons in the water molecule. The relative positions of the sites can be viewed as being situated in a tetrahedral arrangement on the sphere. These interactions are used to describe the hydrogen-bonded interactions between water molecules. Cations and anions are modelled as charged hard spheres of specified diameter, e.g. $\sigma_{22}$ and $\sigma_{33}$.

In addition, all these hard spheres have attractive van der Waals interactions that are modelled using a square well potential. The total attraction-repulsion interactions between the hard spheres $i$ and $j$ are thus described by the potential energy function $\mathrm{u}_{\mathrm{ij}}(\mathrm{r})$ :

$$
u_{i j}(r)=\left\{\begin{array}{c}
+\infty, r<\sigma_{i j} \\
-\varepsilon_{i j}, \sigma_{i j} \leq r \leq \sigma_{i j} \lambda_{i j} \\
0, r \geq \sigma_{i j} \lambda_{i j}
\end{array}\right\}
$$

where

$$
\sigma_{\mathrm{ij}}=\frac{\sigma_{\mathrm{ii}}+\sigma_{\mathrm{jj}}}{2}
$$

and where a hard sphere $\mathrm{i}$ is characterised by three parameters, namely the hard sphere diameter $\sigma_{\mathrm{ii}}$, the square well range $\lambda_{\mathrm{ii}}$, which is the range of dispersion interactions, and the square well depth $\varepsilon_{\mathrm{ii}}$, which is the strength of dispersion interactions. The values of these parameters depend on which particles make up the pair, hence the variable range description. More details are given in the literature. ${ }^{25,27}$ 
Ion-ion interactions are considered to be Coulombic in nature. Interactions via a square well potential are not considered, because good fits to the activity coefficients of nitric acid and uranyl nitrate can still be achieved. It is probable that even greater accuracy could be achieved by including such terms. Similarly, the quality of the fit meant there was no need to consider the presence of any undissociated electrolyte. ${ }^{37}$

\subsection{Predicting activity coefficients}

The total residual Helmholtz free energy of the mixture, $A^{R}$, is given by:

$$
\frac{\mathrm{A}^{\mathrm{R}}}{\mathrm{NkT}}=\frac{\mathrm{A}^{\mathrm{MONO}}}{\mathrm{NkT}}+\frac{\mathrm{A}^{\mathrm{CHAIN}}}{\mathrm{NkT}}+\frac{\mathrm{A}^{\mathrm{ASSOC}}}{\mathrm{NkT}}+\frac{\mathrm{A}^{\mathrm{ION}}}{\mathrm{NkT}}
$$

Here $\mathrm{k}$ is Boltzmann's constant, $\mathrm{N}$ is the total number of molecules and ions and $\mathrm{T}$ is the temperature in Kelvin. ${ }^{27} \mathrm{~A}^{\mathrm{MONO}}$ is the residual free energy due to hard core and dispersion interactions between monomers, $\mathrm{A}^{\mathrm{CHAIN}}$ is the residual free energy contribution from chain formation, $\mathrm{A}^{\mathrm{ASSOC}}$ is the residual free energy contribution from intermolecular association and $\mathrm{A}^{\mathrm{ION}}$ is the residual free energy contribution due to Coulombic interactions between the ions. SAFT-VRE expressions for $\mathrm{A}^{\mathrm{MONO}}, \mathrm{A}^{\mathrm{ASSOC}}$ and $\mathrm{A}^{\mathrm{ION}}$ in terms of the various SAFT-VRE parameters including the hard sphere diameter $\sigma$, the square well range $\lambda$ and square well depth $\varepsilon$, can be found in the literature. ${ }^{26,27}$ For the aqueous solution of nitric acid and uranyl nitrate, no chains are present and so $\mathrm{A}^{\mathrm{CHAIN}}$ is zero.

Activity coefficients are among the physical properties that can be calculated from the Helmholtz free energy via thermodynamic relationships. Activity coefficients are of particular importance for the modelling of actinide ions in solution and, hence, the simulation of solvent extraction-based processes for separation of actinides, as used in spent nuclear fuel reprocessing. For application to electrolyte solutions, the mean activity coefficient of the 
electrolyte compound is used. The mean activity coefficient for compound $\mathrm{A}^{\mathrm{q}+}{ }_{\mathrm{p}} \mathrm{B}^{\mathrm{p}-}{ }_{\mathrm{q}}$ can be calculated from the total residual Helmholtz free energy $A^{\mathrm{R}}{ }^{38}$

$$
\begin{aligned}
& \mu_{\mathrm{i}}^{\mathrm{R}}=\frac{1}{\mathrm{~V}}\left[\frac{\partial \mathrm{A}^{\mathrm{R}}}{\partial \rho_{\mathrm{i}}}\right]_{\mathrm{V}, \mathrm{T}} \\
& \ln \gamma_{\mathrm{i}}=\frac{1}{\mathrm{kT}}\left(\mu_{\mathrm{i}}^{\mathrm{R}}-\mu_{\mathrm{i}}^{\mathrm{R}, \infty}\right) \\
& \ln \gamma_{ \pm}=\frac{\mathrm{p} \ln \gamma_{+}+\mathrm{q} \ln \gamma_{-}}{\mathrm{p}+\mathrm{q}}
\end{aligned}
$$

where $\rho_{i}$ is the number density of species $i, \mu_{i}^{R}$ is its residual chemical potential, $\mu_{i}^{R, \infty}$ is the residual chemical potential at infinite dilution, $\gamma_{\mathrm{i}}$ is the activity coefficient of species $i$ where $i$ can be molecular water or any cation, or anion present in the system $. \gamma_{+}, \gamma_{-}$are the activity coefficient of cation $\mathrm{A}^{\mathrm{q}+}$ and anion $\mathrm{B}^{\mathrm{p}-}$ respectively while $\gamma_{ \pm}$is the mean activity coefficient of the compound $\mathrm{A}^{\mathrm{q}+}{ }_{\mathrm{p}} \mathrm{B}^{\mathrm{p}-}{ }_{\mathrm{q}}$.

\subsection{Predicting solution density}

As the total residual Helmholtz free energy $A^{R}$ can be calculated from SAFT-VRE, ${ }^{26,27}$ based on thermodynamic relationships, the compressibility factor, $\mathrm{Z}$, can then be calculated from $\mathrm{A}^{\mathrm{R}}: 39$

$$
\begin{aligned}
& \mathrm{Z}=1+\mathrm{V}\left(\frac{\partial \mathrm{A}^{\mathrm{R}}}{\partial \mathrm{V}}\right) \\
& \mathrm{V}=\frac{\mathrm{N}}{\mathrm{Avg}} \mathrm{V}_{\mathrm{m}}
\end{aligned}
$$

where $\mathrm{V}$ is the volume of the system, $\mathrm{A}_{\mathrm{vg}}$ is the Avogadro constant, $\mathrm{V}_{\mathrm{m}}$ is the molar volume of the mixture, and $\mathrm{N}$ is the total number of molecules and ions present. The molar volume, $\mathrm{V}_{\mathrm{m}}$, is related to the compressibility factor, $\mathrm{Z}$, by:

$$
\mathrm{V}_{\mathrm{m}}=\frac{\mathrm{ZRT}}{\mathrm{P}}
$$

The liquid density of a solution, $\rho$, is given by: 


$$
\rho=\frac{\sum_{\mathrm{i}=1, \mathrm{n}} \mathrm{M}_{\mathrm{i}} \mathrm{x}_{\mathrm{i}}}{\mathrm{V}_{\mathrm{m}}}
$$

where $M_{i}$ is the molecular weight of species $i$ and $x_{i}$ is its mole fraction in the mixture.

\subsection{Distribution coefficient modelling}

A widely used approach for calculating distribution coefficients is to treat extraction as a reaction between a species in the aqueous phase and an extraction agent in the organic phase. $^{16,17,40-42}$ The distribution coefficients can be calculated from the equilibrium constant and activities of the species. In this approach, the non-ideal behaviour of the organic phase can be included in experimental fitting parameters, organic activity coefficients then being taken as unity. The non-ideal behaviour of the electrolyte solution is described by activity coefficients. Due to the complex composition of reprocessing solutions used in an advanced PUREX process and the non-ideal behaviour of the electrolyte solution in that process, these activity coefficients are not easy to calculate and are usually represented by empirical correlations. However, the SAFT-VRE method provides a more fundamental approach to calculate these activities. This work treats extraction of nitric acid and uranyl nitrate by TBP as extraction reactions, as proposed by Rozen et al., ${ }^{40}$ where the concentrations of $\mathrm{HNO}_{3}$ and uranium in $30 \%$ TBP can be calculated as follows:

$$
\begin{aligned}
& \mathrm{C}_{\mathrm{H} 1, \text { or }}=\overline{\mathrm{K}}_{\mathrm{H} 1} \mathrm{C}_{\mathrm{H}^{+}, \mathrm{aq}} \mathrm{C}_{\mathrm{NO}_{3}^{-}, \mathrm{aq}} \gamma_{\mathrm{H}^{+}} \gamma_{\mathrm{NO}_{3}^{-}} \mathrm{C}_{\mathrm{TBP}, \text { or }} \\
& \mathrm{C}_{\mathrm{H} 2, \text { or }}=\overline{\mathrm{K}}_{\mathrm{H} 2} \mathrm{C}_{\mathrm{H}^{+}, \mathrm{aq}} \mathrm{C}_{\mathrm{NO}_{3}^{-}, \mathrm{aq}} a_{W} \gamma_{\mathrm{H}^{+}} \gamma_{\mathrm{NO}}^{-} \mathrm{C}_{\mathrm{TBP}, \text { or }}^{2} \\
& \mathrm{C}_{\mathrm{H} 1 / 2, \text { or }}=\overline{\mathrm{K}}_{\mathrm{H} 1 / 2} \mathrm{C}_{\mathrm{H}^{+}, \mathrm{aq}}^{2} \mathrm{C}_{\mathrm{NO}_{3}^{-}, \mathrm{aq}}^{2} \gamma_{\mathrm{H}^{+}}^{2} \gamma_{N O_{3}^{-}}^{2} a_{W} \mathrm{C}_{\mathrm{TBP}, \text { or }} \\
& \mathrm{C}_{\mathrm{H}, \text { or }}=\mathrm{C}_{\mathrm{H} 1, \text { or }}+\mathrm{C}_{\mathrm{H} 2, \text { or }}+2 \mathrm{C}_{\mathrm{H} 1 / 2, \text { or }} \\
& \mathrm{C}_{\mathrm{U}, \text { or }}=\overline{\mathrm{K}}_{\mathrm{U}} \mathrm{C}_{\mathrm{U}, \mathrm{aq}} \mathrm{C}_{\mathrm{NO}_{3}^{-}, \mathrm{aq}}^{2} \gamma_{\mathrm{UO}_{2}^{2}} \gamma_{N O_{3}^{-}}^{2} \mathrm{C}_{\mathrm{TBP}, \text { or }}^{2}
\end{aligned}
$$


where subscripts aq and or indicate the aqueous and organic phases, respectively, $\overline{\mathrm{K}}_{\mathrm{i}}$ is the effective equilibrium constant of species i defined as follows: W is water, and H1, H2 and $\mathrm{H} 1 / 2$ are the mono-solvate $\left(\mathrm{HNO}_{3} \cdot \mathrm{TBP}\right)$, di-solvate $\left(\mathrm{HNO}_{3} \cdot \mathrm{H}_{2} \mathrm{O} \cdot(\mathrm{TBP})_{2}\right)$ and semi-solvate $\left(\left(\mathrm{HNO}_{3}\right)_{2} \cdot \mathrm{H}_{2} \mathrm{O} \cdot \mathrm{TBP}\right)$ species, ${ }^{40}$ respectively. In contrast to the SEPHIS model, ${ }^{17}$ Rozen's model introduced the semi-solvate nitric acid species and considered both the di-solvate nitric acid species and the semi-solvate nitric acid species to be hydrated. In this way, Rozen's model provided a good description of nitric acid and water extraction. ${ }^{40}$

The activity coefficients in Eqs. (11-15) can be calculated from the SAFT-VRE model. The free TBP concentration, $\mathrm{C}_{\mathrm{TBP}, \text { or }}$, if we neglect the extraction of other actinides, can be calculated from the mass balance:

$$
\mathrm{C}_{\mathrm{TBP}, \text { total,or }}=\mathrm{C}_{\mathrm{TBP}, \text { or }}+2 \mathrm{C}_{\mathrm{U}, \mathrm{or}}+2 \mathrm{C}_{\mathrm{H} 2, \mathrm{or}}+\mathrm{C}_{\mathrm{H} 1, \mathrm{or}}+\mathrm{C}_{\mathrm{H} 1 / 2, \mathrm{or}}
$$

The effective equilibrium constants for acid and uranium can be calculated by Eq.(17), and the parameters $\mathrm{K}_{\mathrm{i}, 0}$ and $\mathrm{E}_{\mathrm{i}}$ are regressed against experimental data. This also means that the non-ideal behaviour of the organic phase is included in these experimental fitting parameters.

$$
\overline{\mathrm{K}}_{\mathrm{i}}=\mathrm{K}_{\mathrm{i}, 0} \mathrm{e}^{-\frac{\mathrm{E}_{\mathrm{i}}}{\mathrm{RT}}} \quad(\text { where } \mathrm{i}=\mathrm{H} 1, \mathrm{H} 2, \mathrm{H} 1 / 2, \mathrm{U})
$$

The neptunium distribution coefficients are calculated following the approach of Chen et al.. ${ }^{21}$ In which the distribution coefficient of neptunium (V) was set to $0.01^{18}$ and the distribution coefficient of neptunium (VI) was calculated from aqueous concentrations using the model of Kolarik and Petrich. ${ }^{15}$ The parameters of this model were fitted to the KfK4660 dataset. $^{43}$ The redox reaction between neptunium (V) and (VI) in aqueous and organic phase were calculated based on redox kinetics published in the literature. ${ }^{21,44}$ The disproportionation of neptunium (V) was neglected. ${ }^{21}$ The distribution coefficient of nitrous acid was calculated from the empirical equation published by Tachimori. ${ }^{18}$ 


\section{APPLICATION OF SAFT-VRE FOR CALCULATION OF DISTRIBUTION}

\section{COEFFICIENTS}

This work uses the least squares regression function in MATLAB to estimate the distribution coefficient model parameters $\mathrm{K}_{0}$ and $\mathrm{E}$ from nitric acid and uranium distribution coefficient data in the KfK3080 data set. ${ }^{21}$ The pressure is constant (101,325 Pa). It is assumed that nitric acid fully dissociates to nitrate and hydronium ions. The activity coefficients of water, hydronium, nitrate and uranyl are calculated by SAFT-VRE. The parameters $\sigma_{\mathrm{ii}}, \varepsilon_{\mathrm{ii}}$ and $\lambda_{\mathrm{ii}}$ for species $\mathrm{i}$ were obtained by Pelendritis, ${ }^{37}$ via regression against experimental data obtained at $298.15 \mathrm{~K}$ for the uranyl nitrate and nitric acid activity coefficients; the values are listed in Table 1 . For water, the parameters $\sigma_{\mathrm{ii}}, \varepsilon_{\mathrm{ii}}$ and $\lambda_{\mathrm{ii}}$ were obtained from the literature, ${ }^{27}$ along with $\mathrm{r}_{\mathrm{d} 1}, \mathrm{r}_{\mathrm{c} 1}$ and $\varepsilon_{11}^{\mathrm{HB}}$.

Table 1: Molecular simulation parameters

\begin{tabular}{lccccl}
\hline & $i$ & $\sigma_{\mathrm{ii}}\left(10^{-10} \mathrm{~m}\right)$ & $\varepsilon_{\mathrm{ii}} / k(\mathrm{~K})^{*}$ & $\lambda_{\mathrm{ii}}$ & \multicolumn{1}{c}{ Source } \\
\hline Water & 1 & 3.036 & 253.3 & 1.8 & Galindo et al. $^{27}$ \\
Hydronium & 2 & 3.036 & 750 & 1.2 & Pelendritis ${ }^{37}$ \\
Nitrate & 3 & 3.4 & 313 & 1.2 & Pelendritis ${ }^{37}$ \\
Uranyl & 4 & 3.57 & 1250 & 1.2 & Pelendritis $^{37}$ \\
\hline
\end{tabular}

$* k$ is the Boltzmann constant

Eight sets of data from the KfK3080 data set were used, together with Eq.(17), to estimate the parameters of the distribution coefficient model. The regressed parameters needed for the distribution coefficient model are listed in Table 2. Table 3 highlights which data from KfK3080 were used for model fitting and also lists the percentage average absolute deviation $(\% \mathrm{AAD})$ of the predicted distribution coefficients at various temperatures. Predictions using the conventional method ${ }^{16,17}$ that is used in the SEPHIS code to calculate the distribution coefficient of nitric acid and uranyl nitrate between aqueous solutions and 30\% TBP solvent 
(notes as SEPHIS model follow on) and the new approach are summarised and compared in Table 3.

Table 2: Distribution coefficient model parameters

\begin{tabular}{ccccc}
\hline & $\begin{array}{c}\text { Mono-solvate } \\
(\mathrm{H} 1)\end{array}$ & $\begin{array}{c}\text { Di-solvate } \\
(\mathrm{H} 2)\end{array}$ & $\begin{array}{c}\text { Semi-solvate } \\
(\mathrm{H} 1 / 2)\end{array}$ & Uranium \\
& 6.71 & $2.05 \times 10^{-5}$ & 10.46 & 11.41 \\
$\mathrm{E}(\mathrm{J} / \mathrm{mol})$ & 9445.04 & -15379.50 & 44935.47 & -4408.42 \\
\hline
\end{tabular}

Table 3 Regression of distribution coefficient models and validation against KfK3080 data

\begin{tabular}{|c|c|c|c|c|c|c|c|}
\hline $\mathrm{K}$ & $\begin{array}{c}\text { No. of } \\
\text { data } \\
\text { points }\end{array}$ & $\begin{array}{l}\mathrm{C}_{\mathrm{HNO} 3} \\
\mathrm{~mol} / \mathrm{L}\end{array}$ & $\begin{array}{c}\mathrm{C}_{\mathrm{U}} \\
\mathrm{mol} / \mathrm{L}\end{array}$ & $\begin{array}{l}\% \text { AAD } \\
\text { SEPHIS }\end{array}$ & $\begin{array}{l}\mathrm{f}_{\mathrm{HNO}} \\
\text { SAFT- } \\
\text { VRE }\end{array}$ & $\begin{array}{l}\% \text { AAD } \\
\text { SEPHIS }\end{array}$ & $\begin{array}{c}\mathrm{f}_{\mathrm{U}}, \% \\
\text { SAFT- } \\
\text { VRE }\end{array}$ \\
\hline 288 & 2 & $0.1,0.2$ & - & 30.11 & 11.64 & - & - \\
\hline 293 & $41^{*}$ & $0.1 \sim 10.29$ & - & 6.17 & 10.25 & - & - \\
\hline 293 & $70 *$ & $0.05 \sim 6.13$ & $4 \times 10^{-5} \sim 1.01$ & 11.04 & 19.20 & 6.80 & 24.40 \\
\hline 295 & $19 *$ & $0.02 \sim 8.94$ & - & 10.49 & 4.12 & - & - \\
\hline 296 & 15 & $0.2 \sim 9.06$ & - & 5.91 & 11.64 & - & - \\
\hline 298 & $43^{*}$ & $0.02 \sim 5.91$ & - & 9.26 & 10.71 & - & - \\
\hline 298 & $160^{*}$ & $0.02 \sim 5.12$ & $8 \times 10^{-5} \sim 1.04$ & 24.16 & 28.96 & 6.40 & 16.35 \\
\hline 299 & 14 & $1.97 \sim 4.04$ & $1.7 \times 10^{-3} \sim 1.24$ & 11.10 & 19.66 & 5.68 & 14.04 \\
\hline 303 & 16 & $0.1 \sim 6.48$ & - & 3.94 & 5.55 & - & - \\
\hline 303 & 9 & $1.68 \sim 2.28$ & $4 \times 10^{-5} \sim 1.02$ & 19.84 & 21.10 & 0.97 & 10.25 \\
\hline 313 & $17 *$ & $0.048 \sim 8.19$ & - & 6.11 & 2.13 & - & - \\
\hline 313 & $28 *$ & $0.27 \sim 3.91$ & $0.01 \sim 1.13$ & 22.37 & 30.40 & 3.59 & 5.15 \\
\hline 318 & 4 & $1.02 \sim 4$ & - & 4.57 & 4.22 & - & - \\
\hline 318 & 19 & $1.05 \sim 4.74$ & $0.007 \sim 0.81$ & 13.14 & 22.04 & 5.36 & 16.76 \\
\hline 323 & 1 & 1.73 & - & 6.14 & 9.29 & - & - \\
\hline 323 & 19 & $0.46 \sim 2.04$ & $4 \times 10^{-5} \sim 1.03$ & 20.26 & 24.12 & 5.66 & 7.45 \\
\hline 328 & 2 & 1.5 & $0.13,0.24$ & 17.23 & 16.77 & 7.43 & 4.55 \\
\hline 333 & $23^{*}$ & $0.05 \sim 7.96$ & - & 8.88 & 4.66 & - & - \\
\hline 333 & $51^{*}$ & $0.02 \sim 4.65$ & $0.01 \sim 1.09$ & 25.87 & 29.78 & 7.61 & 12.13 \\
\hline 343 & 1 & 1.69 & - & 1.84 & 1.03 & - & - \\
\hline 343 & 49 & $0.67 \sim 4.18$ & $1.68 \times 10^{-4} \sim 1.06$ & 12.95 & 14.57 & 8.04 & 9.10 \\
\hline
\end{tabular}

*Used for parameter estimation

As can be seen in Table 3, for nitric acid - water binary system both models can predict nitric acid distribution coefficients reasonably well over a range of temperatures and acid 
concentrations. The model applying the SAFT-VRE method fits the experimental data better in the range $313-333 \mathrm{~K}$ than the SEPHIS model. The overall \%AAD for the calculated nitric acid distribution coefficients for 182 data points where uranium is not present are similar $7.8 \%$ for the SAFT-VRE method and $7.7 \%$ for the SEPHIS model. $90 \%$ of the prediction errors are less than $14 \%$ for SEPHIS and $16 \%$ for SAFT-VRE, while $80 \%$ of the prediction errors are less than $9 \%$ for SAFT-VRE and 12\% for SEPHIS. It may be concluded that, for the nitric acid-water system, the nitric acid distribution coefficients are predicted equally accurately by the new method and the SEPHIS model. The results of the distribution coefficient calculation in the $\mathrm{HNO}_{3}$-water system also suggest that the SAFT-VRE parameters in Table 1 can be used in mean activity calculations at other temperatures.

When uranium is present, both methods give less accurate predictions of the nitric acid distribution coefficients. The SAFT-VRE method is also less accurate than the SEPHIS model. The \%AAD of predictions, compared to the KfK3080 data set of 421 distribution coefficients of nitric acid with uranium present, are $25 \%$ by the SAFT-VRE model and 20\% by the SEPHIS model.

The deviation (\%AAD) between calculated uranium distribution coefficients for uranium and $421 \mathrm{KfK} 3080$ data is $15 \%$ for the SAFT-VRE method and $6 \%$ for the SEPHIS model. It is evident that both approaches are more accurate for predicting uranium distribution than $\mathrm{HNO}_{3}$ distribution when uranium is present, but clearly the fitted SEPHIS model is more accurate than the predictive SAFT-VRE approach. The errors in the calculation of distribution coefficients in $\mathrm{UO}_{2}\left(\mathrm{NO}_{3}\right)_{2}-\mathrm{HNO}_{3}$ system imply the current activity coefficient calculation by SAFT-VRE in a multiple salt system is not as accurate as in a binary system. 
The accuracy of the calculation of distribution coefficients by SAFT-VRE can be improved. The SAFT-VRE method itself is subject to ongoing development. For example, in this work, ion-ion dispersion interactions were neglected. No doubt the quality of the model could be improved by including such terms. Furthermore, non-ideal effects in the organic phase were treated via the $\mathrm{K}_{0}$ and E parameters. Further developments of the SAFT method might lead to the ability to describe the non-ideal effects in organic phases and thereby improve the predictive capabilities of the model.

\section{APPLICATION OF SAFT-VRE FOR PREDICTING AQUEOUS SOLUTION}

\section{DENSITY}

In this work, the SAFT-VRE calculations are implemented using gSAFT 3.0®, which was developed by Process Systems Enterprise. ${ }^{45}$ The model parameters ( $\sigma_{\mathrm{ii}}, \varepsilon_{\mathrm{ii}}$ and $\lambda_{\mathrm{ii}}$ of the ions) are the same as those listed in Table 1 . The parameters for water are taken directly from the gSAFT 3.0 databank, and are consistent with the literature. ${ }^{46}$

The gSAFT 3.0 results are compared with 478 experimental density data from the literature in Table 4, which lists five sources of experimental data and the \%AAD of the SAFT-VRE method, compared with results of our earlier empirical method. ${ }^{20}$ The temperature range is $283-348 \mathrm{~K}$, the uranium concentration range is $0-2.2 \mathrm{~mol} / \mathrm{L}$ and the nitric acid concentration range is $0-7.2 \mathrm{~mol} / \mathrm{L}$. The effects of temperature on the measurement of concentration are neglected. The deviation (\%AAD) in predicted density is $0.2-1.6 \%$ for SAFT-VRE and $0.1-$ $1.5 \%$ for the model of Chen et al. ${ }^{20}$ The result shows that the SAFT-VRE method can predict density for a range of temperatures, concentrations and densities, at least as well as the empirical method ${ }^{20}$ and, therefore, can be used to provide reliable predictions for use in flowsheet simulations. 
Table 4 Comparison of density predictions using SAFT-VRE and the empirical method

\begin{tabular}{|c|c|c|c|c|c|c|}
\hline Data source & $\begin{array}{c}\text { Tempera } \\
\text { ture } \\
(\mathrm{K})\end{array}$ & $\begin{array}{c}\text { No. of } \\
\text { data } \\
\text { points }\end{array}$ & $\begin{array}{l}\text { Uranium } \\
(\mathrm{mol} / \mathrm{L})\end{array}$ & $\begin{array}{c}\text { Nitric acid } \\
(\mathrm{mol} / \mathrm{L})\end{array}$ & $\begin{array}{l}\text { \%AAD of } \\
\text { SAFT-VRE }\end{array}$ & $\begin{array}{l}\text { \%AAD of } \\
\text { empirical } \\
\text { method }^{20}\end{array}$ \\
\hline Botts, et al. ${ }^{47}$ & $298 \sim 348$ & 198 & $0.04 \sim 1.10$ & $0.088 \sim 1.75$ & 0.72 & 0.76 \\
\hline Cauchetier ${ }^{48}$ & $288 \sim 313$ & 78 & 0 & $0 \sim 8$ & 0.93 & 0.30 \\
\hline Boualia, et al. ${ }^{49}$ & 298 & 34 & $0.004 \sim 1.34$ & $0.025 \sim 1.25$ & 1.57 & 1.48 \\
\hline $\mathrm{Yu}$, et al. ${ }^{50}$ & 298 & 42 & $0.1 \sim 0.4$ & $1 \sim 4$ & 0.15 & 0.11 \\
\hline $\begin{array}{l}\text { Sakurai \& } \\
\text { Tachimori, }\end{array}$ & $283 \sim 333$ & 126 & $0 \sim 2.23$ & $0 \sim 7.2$ & 0.78 & 1.10 \\
\hline
\end{tabular}

\section{FLOWSHEET SIMULATIONS}

The aqueous-phase density model and the distribution coefficient model for nitric acid and uranium based on SAFT-VRE are then applied to simulate the single-stage and multi-stage neptunium extraction processes described in Taylor et al. ${ }^{10}$ The flowsheet simulation code has been described previously ${ }^{20,21}$ and is implemented in gPROMS 4.2. ${ }^{52}$ Activity coefficients of nitric acid and uranyl nitrate are calculated using the SAFT-VRE method, coded in Fortran 77 and compiled with the Intel Visual FORTRAN Compiler 11.1 to create a dynamic link library (DLL) file. The dynamic link library file then links to the flowsheet simulation code through a foreign object interface set up in gPROMS. Since the SAFT-VRE parameters for neptunium and nitrous acid are unavailable at present, the distribution coefficients of neptunium (VI), neptunium (V) and nitrous acid are calculated using the empirical method presented by Chen et al.. ${ }^{21}$ The aqueous-phase density is calculated by the SAFT-VRE method, also using the gSAFT 3.0 package within gPROMS 4.2. Since the concentrations of neptunium and nitrous acid are low, their influence on the aqueous-phase density is neglected. Other simulation models and parameters such as the redox kinetic models and parameters, and the mass transfer models and mass transfer coefficients are the same as in our previous work. ${ }^{21}$ 


\subsection{Simulation of single-stage centrifugal contactor trials}

Initially, fifteen neptunium extraction experiments ${ }^{10}$ in single-stage centrifugal contactors, without uranium present, were simulated. Figure 1 presents the simulation results. It may be seen that the model predictions are in reasonable agreement with Taylor's experimental results: ${ }^{10}$ the mean absolute error (MAE) of these 15 simulations $(0.075)$ is very close to the MAE of 0.073 for the results presented by Chen et al.. ${ }^{21}$ As the neptunium distribution coefficients are not predicted using the SAFT-VRE method, the similarity between these results is understandable - the main difference between the two methods is how the nitric acid distribution coefficient and aqueous-phase density are calculated.

\subsection{Multi-stage flowsheet simulation with SAFT-VRE}

Following the simulation of single stage trials, this model was applied to simulate a multistage advanced PUREX extract-scrub flowsheet, based on an experiment reported by Taylor et al. ${ }^{10}$ and depicted in Scheme 1. The accuracy of the flowsheet simulation results to Taylor's experimental results ${ }^{10}$ is presented in Figure 2 in terms of \%AAD.

Figure 2 shows that the SAFT-VRE method can improve predictions of nitric acid distribution in this flowsheet. Figure 3 shows that, as a consequence, the simulated concentration profile for the aqueous nitric acid, using the SAFT-VRE model, is close to that obtained using the SEPHIS model. In the organic phase, the simulation results with the SAFT-VRE model agree better with Taylor's experimental data ${ }^{10}$ than those of the SEPHIS model. The nitric acid distribution coefficients predicted by the SAFT-VRE model are generally higher than those of the SEPHIS model, as indicated by comparison of nitric acid concentration profiles predicted by the two methods shown in Figure 3. 


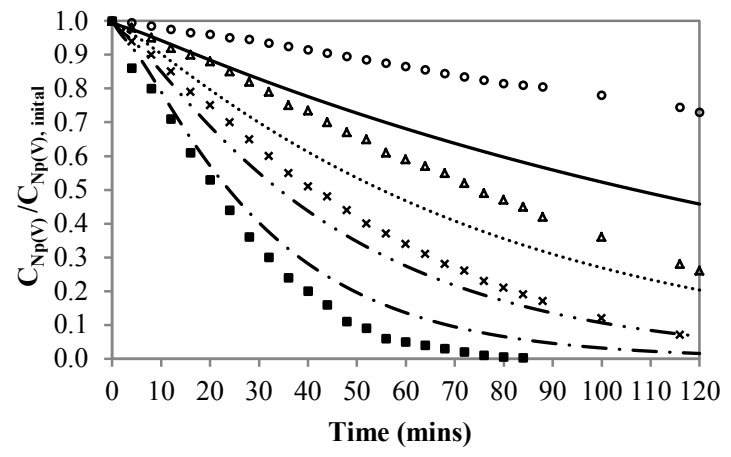

$$
\begin{aligned}
& \text { - Expt.3, } 2 \mathrm{~mol} / \mathrm{L} \Delta \quad \text { Expt. } 4,3 \mathrm{~mol} / \mathrm{L} \\
& \text { × Expt.5, } 4 \mathrm{~mol} / \mathrm{L} \quad \text { - Expt. } 6,5 \mathrm{~mol} / \mathrm{L} \\
& \text { Simul.3, } 2 \mathrm{~mol} / \mathrm{L} \quad \ldots \ldots \ldots . . . . . . . \text { Simul. } 4,3 \mathrm{~mol} / \mathrm{L}
\end{aligned}
$$

(a)

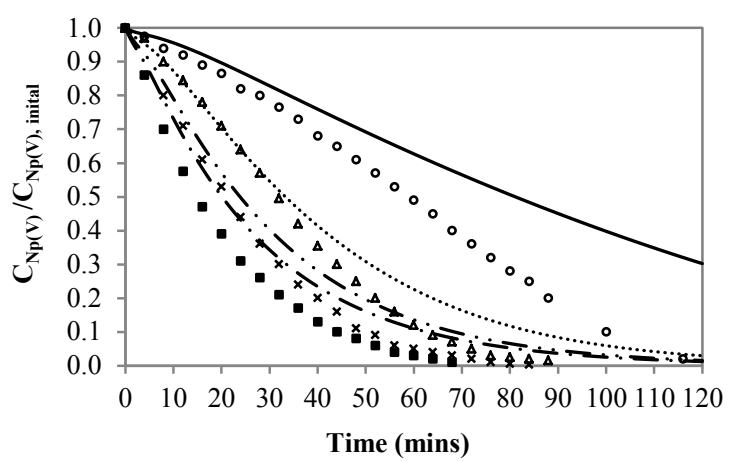

$$
\begin{array}{ccccc}
\circ & \text { Expt.9, } 0.5 \mathrm{mmol} / \mathrm{L} & \Delta & \text { Expt.8, } 3 \mathrm{mmol} / \mathrm{L} \\
\times & \text { Expt.6, } 10 \mathrm{mmol} / \mathrm{L} & \text { - } & \text { Expt.7, } 30 \mathrm{mmol} / \mathrm{L} \\
& \text { Simul.9, } 0.5 \mathrm{mmol} / \mathrm{L} & \ldots \ldots \ldots \ldots \ldots . . & \text { Simul. } 8,3 \mathrm{mmol} / \mathrm{L}
\end{array}
$$
- - - Simul.6, $10 \mathrm{mmol} / \mathrm{L}$

(c)

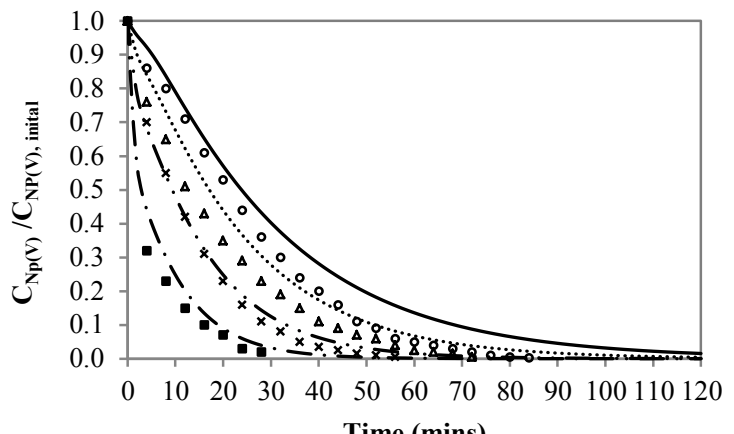

Time (mins)

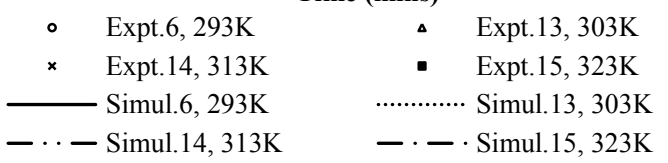

(b)

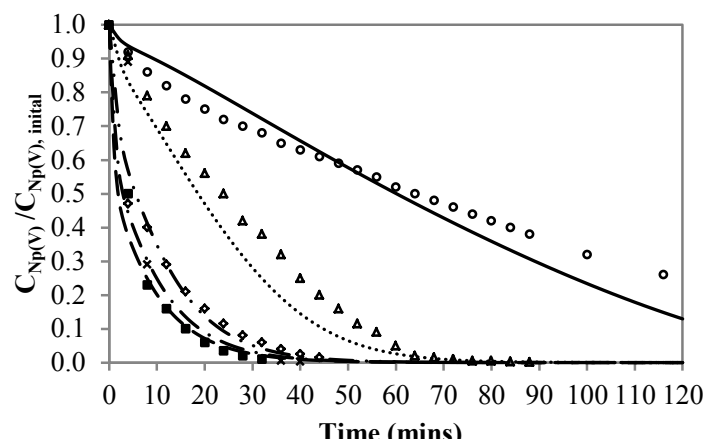

- Expt.12,0.1 mmol/L $/ \mathrm{L}$ Expt.11, $0.5 \mathrm{mmol} / \mathrm{L}$

* Expt.10,3 mmol/L - Expt. $15,10 \mathrm{mmol} / \mathrm{L}$

- Expt.16, $60 \mathrm{mmol} / \mathrm{L} \longrightarrow$ Simul.12, $0.1 \mathrm{mmol} / \mathrm{L}$ Simul.11, $0.5 \mathrm{mmol} / \mathrm{L} \quad-\cdots-$ Simul. $10,3 \mathrm{mmol} / \mathrm{L}$

— - - Simul.15, $10 \mathrm{mmol} / \mathrm{L} \quad$ - - - Simul.16, $60 \mathrm{mmol} / \mathrm{L}$

(d)

(a) Variable $\mathrm{HNO}_{3}$ concentration at $293 \mathrm{~K}, 10 \mathrm{mM} \mathrm{HNO}$; (b) Variable temperature with $5 \mathrm{M}$ $\mathrm{HNO}_{3}, 10 \mathrm{mM} \mathrm{HNO}$; (c) Variable $\mathrm{HNO}_{2}$ concentration at $293 \mathrm{~K}, 5 \mathrm{M} \mathrm{HNO}_{3}$; (d) Variable $\mathrm{HNO}_{2}$ concentration at $323 \mathrm{~K}, 5 \mathrm{M} \mathrm{HNO}_{3}$

Figure 1 Simulation of single-stage centrifugal contactor trials using SAFT-VRE (using experimental data reported in ref. ${ }^{10}$ )

Scheme 1. Overview of Taylor's multi-stage advanced PUREX flowsheet 

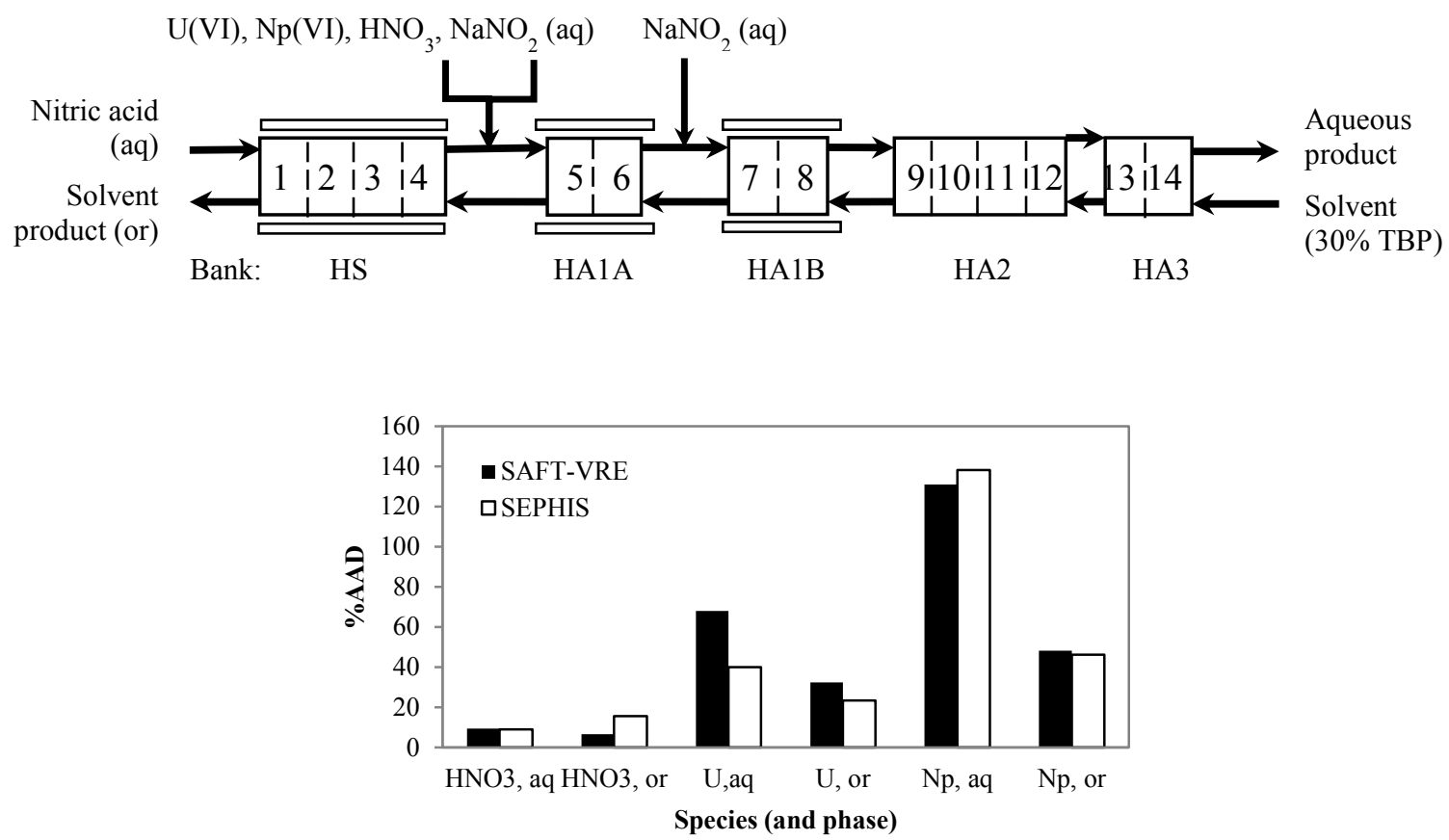

Figure 2 Deviations of the multi-stage flowsheet experimental results ${ }^{10}$ to simulations with SAFT-VRE and SEPHIS models

On the other hand, Figure 4 shows that the uranium concentration profile is predicted less accurately by the SAFT-VRE method than by the SEPHIS model. The experimental data are from Taylor's work. ${ }^{10}$ This result follows from the evidence in Table 3 that the uranium distribution coefficient $\left(\mathrm{D}_{\mathrm{U}}\right)$ is less accurately predicted by the SAFT-VRE model than by the SEPHIS model. Figure 4 shows that the uranium concentrations in both phases predicted using the SAFT-VRE model are lower than those obtained with the SEPHIS model. This is because the uranium distribution coefficients predicted using the SAFT-VRE model are significantly higher than those obtained using the SEPHIS model. Besides the differences of predicted uranium concentrations in HA stages caused by high distribution coefficient of uranium in those stages, the high distribution coefficient value also reduces the uranium concentration in the aqueous phase leaving the feed stage (stage 5), and therefore reduces 
uranium aqueous concentration in all HA stages (stage 5-14). As uranium in the organic phase entering stage 5 is extracted from the aqueous phase in stages 6 to 14, reducing aqueous phase uranium concentrations in stages 6 to 14 also reduces the organic phase uranium concentration in stages 6 to 14 as well as that entering stage 5. The low organic phase uranium concentration entering stage 5 then reduces the uranium concentration in the organic phase output from stage 5 which is fed into HS stages (stages 1 to 4). As in HA stages, the low organic uranium concentrations in the HS stages reduces uranium aqueous concentrations in HS stages. One of the reasons for the errors in the calculation of the distribution coefficients of uranium in the multi-stage simulation is the accuracy of activity coefficients of uranium in nitric acid solutions is not good when the ratio of uranium to nitric acid is low. Further development of the SAFT method such as introduction of interaction parameters for ions and a more complex description of particle interactions should be able to improve the accuracy of the activity coefficient prediction for uranyl nitrate in nitric acid solutions. Further, we currently consider non-ideality of the organic phase by including it in the experimental fitting constant parameter in the uranium distribution coefficient model. Improvements to deal with those non-ideal effects will increase the accuracy of simulation. .

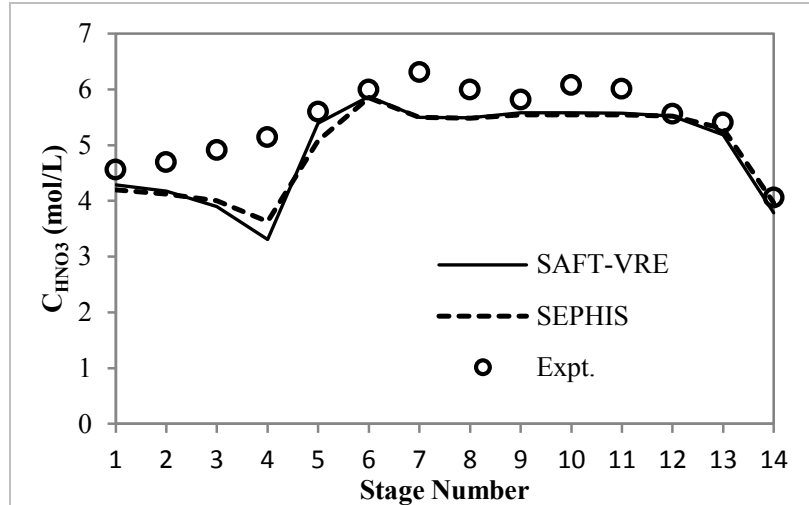

(a)

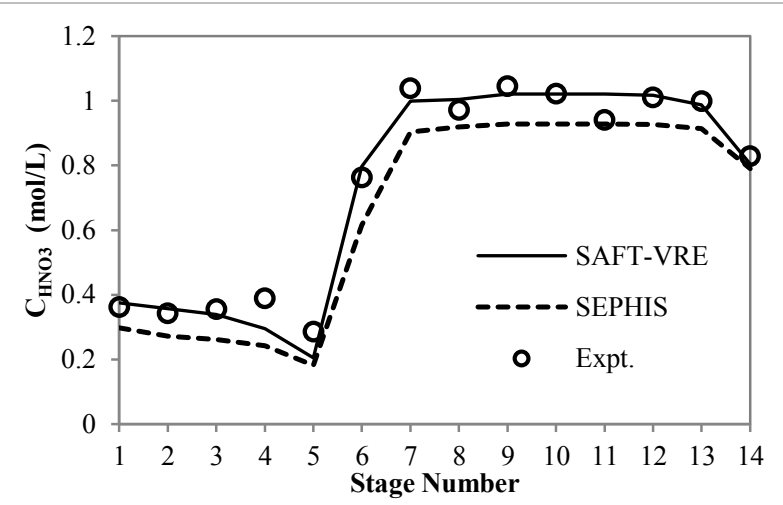

(b) 
Figure 3 Comparison of experimental data of Taylor et al. ${ }^{10}$ with simulation results: Nitric acid profiles for (a) aqueous and (b) organic phases

As shown in Figure 5, compared to the experimental results of Taylor's work, ${ }^{10}$ both models perform reasonably well in simulating neptunium profiles, which is not surprising as neptunium extraction was calculated in both cases using the same approach of Chen et al.. ${ }^{21}$ Nevertheless, there are some contradictory results. As captured by the simulation code, the distribution coefficients of $\mathrm{Np}(\mathrm{VI})$ and nitrous acid both depend on the aqueous-phase uranium and nitric acid concentrations ${ }^{21}$ predicted by the model. Therefore, the difference in the predicted aqueous-phase uranium concentrations in stages 1 to 6 causes the two modelling approaches to predict different neptunium concentrations. The SEPHIS model predicts higher neptunium concentrations in both phases, compared to the concentrations predicted by the SAFT-VRE model.

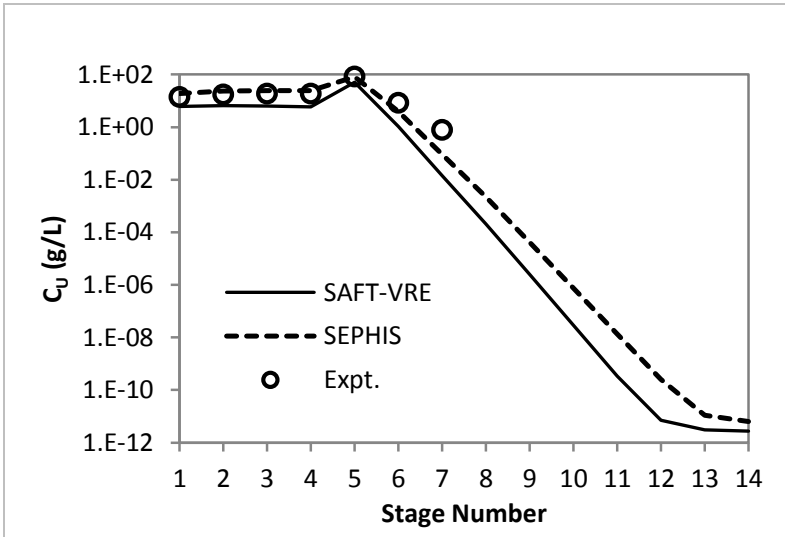

(a)

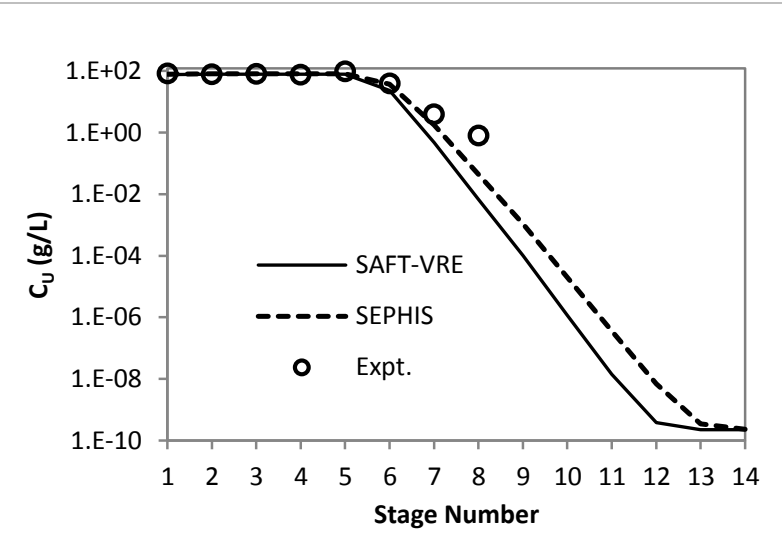

(b)

Figure 4 Comparison of experimental data ${ }^{10}$ with simulation results: Uranium profiles for (a) aqueous and (b) organic phases 


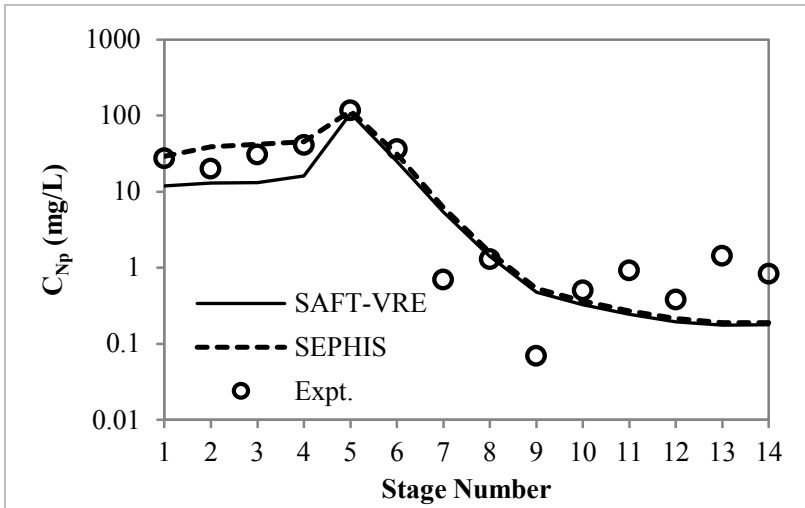

(a)

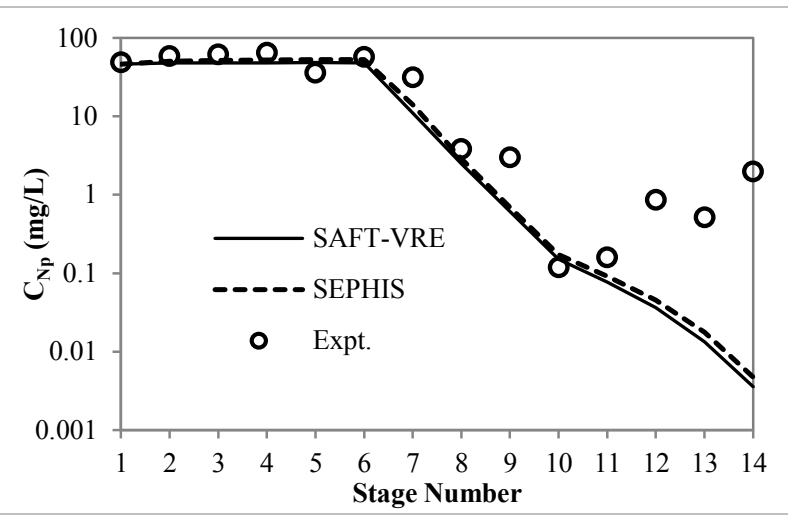

(b)

Figure 5 Comparison of experimental data ${ }^{10}$ with simulation results: Neptunium profiles for (a) aqueous and (b) organic phases

The difference can also be understood by studying the results shown in Figure 6 which presents profiles for neptunium in valence states V and VI calculated by the SAFT-VRE and SEPHIS models. Figure 6 shows that both models predict that, in stages 1-4 (HS bank), neptunium exists primarily in the hexavalent state; therefore, the lower aqueous neptunium concentrations in these stages predicted by the SAFT-VRE model (shown in Figure 5(a)) are due to higher neptunium (VI) distribution coefficients. Again, the higher $\mathrm{Np}$ (VI) distribution coefficient is a direct result of the lower aqueous-phase uranium concentration in the HS bank calculated by the SAFT-VRE model. It is to be expected that improved prediction of uranium distribution coefficients should lead to better prediction of neptunium concentration profiles, because the distribution coefficient of $\mathrm{Np}(\mathrm{VI})$ is dependent on the concentration of aqueous components, including uranium. ${ }^{21}$ 


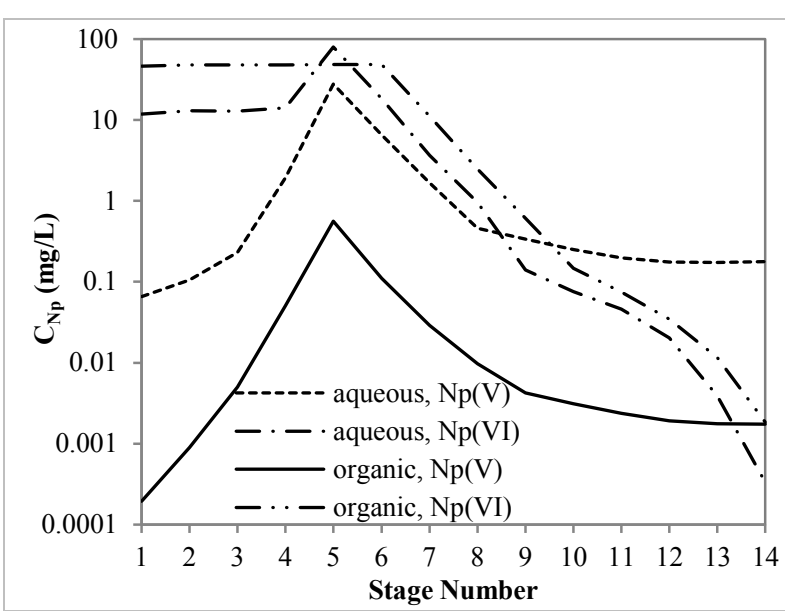

(a)

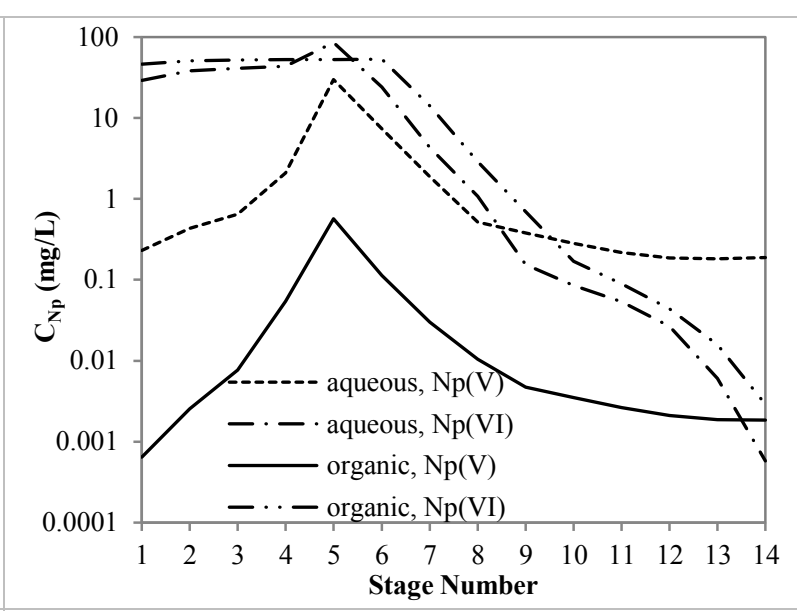

(b)

Figure 6 Profiles of neptunium (V) and (VI) valence states, predicted using (a) the

SAFT-VRE model and (b) the SEPHIS model

\section{CONCLUSIONS}

The ability to model advanced PUREX flowsheets is crucial for the efficient development of flowsheets that can successfully partition uranium and neptunium from spent nuclear fuel. An open source process model developed using gProms, has been developed for this purpose. $^{20,21}$ A lack of adequate predictive methods for estimating thermodynamic and transport properties in these flowsheets continues to hinder progress in this area. This work investigated the potential use of more fundamentally based models based on SAFT-VRE for process modelling of PUREX reprocessing flowsheets. In this case, SAFT-VRE was used to predict distribution coefficients and density in order to simulate such flowsheets.

This work uses a thermodynamic method based on SAFT-VRE to calculate activity coefficients, to allow prediction of distribution coefficients in the flowsheet. The density of the aqueous phase is also calculated by the SAFT-VRE method. In this initial study, the application of SAFT-VRE is limited to the major species, nitric acid and uranium ions neptunium concentrations were calculated using the empirical approach previously described in Chen et al.. ${ }^{20,21}$ 
The average absolute deviation of calculated distribution coefficients of $\mathrm{HNO}_{3}$ and $\mathrm{U}(\mathrm{VI})$ compared to experimental results is shown to be similar for the SAFT-VRE method and the conventional SEPHIS-based model, thus justifying the approach. ${ }^{16,17}$ Furthermore, the SAFTVRE method is shown to give accurate predictions of the aqueous-phase density.

The model has been validated against experimental data from the single-stage and multistage flowsheet experiments of Taylor et al.. ${ }^{10}$ The simulation results using the SAFT-VRE method have also been compared to those obtained using the SEPHIS model. The simulation results for single-stage experiments are generally similar, but some differences are apparent for the multi-stage flowsheet. In particular, SAFT-VRE gave improved predictions of nitric acid concentrations, but worse predictions of the uranium profile. It is believed that errors in the uranium profiles in turn lead to discrepancies in the neptunium profile.

This paper explores, for the first time, the potential of integrating SAFT-VRE based models with gPROMS-based process models for simulation of solvent extraction flowsheets commonly used in actinide separation processes. The SAFT-VRE method uses physically meaningful parameters to calculate the effect of non-ideality in electrolyte solutions, offering the prospect of improvements in the robustness of flowsheet simulation by application of fundamental approaches as opposed to the usual empirical approaches used in solvent extraction models. The results show that SAFT-VRE can successfully support prediction of the aqueous-phase density in this context. Further, with the ongoing development of the SAFT methods, more molecular interactions are becoming available for use in the SAFT calculations. For example, inclusion of the Born contribution to free energy calculations ${ }^{30,36}$ and use of the group contribution approach in $\mathrm{SAFT}^{31,45}$ is now possible. Those modifications will make this method more robust and accurate in the future. Future directions are thus 
opening up to apply these new developments and extend the use of SAFT calculations to a broader range of solvent extraction process simulations.

\section{AUTHOR INFORMATION}

\section{Corresponding Author}

*Hongyan Chen, email: hongyan.chen@manchester.ac.uk.

\section{Author Contributions}

The manuscript was written through contributions of all authors. All authors have given approval to the final version of the manuscript.

\section{Funding Sources}

This work was initially supported by the EPSRC project, 'MBASE: The Molecular Basis of Advanced Nuclear Fuel Separations' EP/1002855/1 followed by an EPSRC Impact Accelerator Account collaborative project with the National Nuclear Laboratory, 'Advanced Spent Nuclear Fuel Process Flowsheet Simulation'. Additional funding was provided by the NNL Internal Research and Development funded Strategic Research program (aqueous recycle project).

\section{ORCID}

Hongyan Chen: 0000-0002-9987-8715 Andrew Masters: 0000-0003-3998-1769; Robin J. Taylor: 0000-0002-3685-277X; Megan Jobson: 0000-0001-9626-5879;

\section{REFERENCES}


(1) Magill, J.; Berthou, V.; Haas, D.; Galy, J.; Schenkel, R. Impact Limits of Partitioning and Transmutation Scenarios on the Radiotoxicity of Actinides in Radioactive Waste. Nuclear Energy 2003, 42, 263-277.

(2) Koch, L. Minor Actinide Transmutation- A Waste Management. J. Less Common Met. 1986, $122,371-382$.

(3) Abderrahim, H. A.; Paillère, H. Strategic Research Agenda, Report of the Sustainable Nuclear Energy Technology Platform. Sustainable Nuclear Energy Technology Platform, 2009, Available at: http://www.snetp.eu/wp-content/uploads/2014/05/sra2009.pdf. [accessed 19 October 2015]

(4) McCarthy, K. A. Nuclear Fuel Cycle Transition Scenario Studies. Nuclear Energy Agency, Organisation for Economic Cooperation and Development, Paris, 2009

(5) Poinssot, C.; Boullis, B. Actinide Recycling Within Closed Fuel Cycles. Nuclear Eng. Int. 2012, 57(670), 17-21.

(6) McFarlane, H. F. Nuclear Fuel Reprocessing. In Encyclopedia of Energy; Cleveland, C. J. Eds.; Elsevier Inc.: New York, 2004

(7) Herbst, R. S.; Baron, P. Standard and Advanced Separation: PUREX Processes for Nuclear. In Advanced Separation Techniques for Nuclear Fuel Reprocessing and Radioactive Waste Treatment; Nash K. L., Lumetta, G. J., Eds.; Woodhouse Publishing Ltd.: Cambridge, 2011; pp. 141-175

(8) Dinh, B.; Moisy, P.; Baron, P.; Calor, J. N.; Espinoux, D.; Lorrain, B.; BenchikouhneRanchoux, M. Modified PUREX First-cycle Extraction for Neptunium Recovery. In 
Proceedings of the International Solvent Extraction Conference; Moyer, B. A. Eds.; Canadian Institute of Mining, Metallurgy and Petroleum: Quebec, Canada, 2008; pp 581-586.

(9) Lecomte, M. E. Treatment and Recycling of Spent Nuclear Fuel: Actinide Partitioning Application to Waste Management; CEA Saclay: Paris, 2008.

(10) Taylor, R. J.; Gregson, C. R.; Carrott, M. J.; Mason, C.; Sarsfield, M. J. Progress Towards the Full Recovery of Neptunium in an Advanced PUREX Process. Solvent Ext. Ion Exch. 2013, 31[4], 442-462.

(11) Taylor, R. J.; Denniss, I. S.; Wallwork, A. L. Neptunium Control in an Advanced Purex Process. Nuclear Energy 1997, 36, 39-46.

(12) Drake, V. A. Extraction Chemistry of Neptunium. In Science and Technology of Tributyl phosphate; Schulz, W. W., Burger, L. L., Navratil J. D., Bender, K. P., Eds.; CRC Press: Boca Raton, FL.,1990; pp 123-145

(13) Yoshida, Z.; Johnson, S. G.; Kimura, T.; Krsul, J. R. Neptunium. In The Chemistry of the Actinide and Transactinide Elements; Morss, L. R., Edelstein N. M., Fuger, J., Eds.; Springer: Netherlands, 2011; pp 699-812.

(14) Kontogeorgis, G. M.; Folas, G. K. Thermodynamic Models for Industrial Applications: From Classical and Advanced Mixing Rules to Association Theories; John Wiley \& Sons: New York, 2010.

(15) Kolarik, Z.; Petrich, G. A Mathematic Model of Distribution Equilibria in the Extraction of $\mathrm{U}(\mathrm{VI}), \mathrm{U}(\mathrm{IV}), \mathrm{Pu}(\mathrm{IV}), \mathrm{Np}(\mathrm{VI}), \mathrm{Np}(\mathrm{IV})$, and Nitric acid by $30 \%$ Tributyl Phosphate (TBP) in Aliphatic Diluents. Ber. Bunsenges. Phys. Chem. 1979, 83, 1110-1113. 
(16) Jubin, R. T.; Whatley, M. E. Revisions to the Mathematical Model Used in the SEPHIS and MATEX Computer Codes for Calculating Distribution Coefficients for U(VI), Pu(IV) and Nitric Acid in the Purex Chemical System; ORNL/TM-9960; Oak Ridge National Laboratory: Oak Ridge, 1986.

(17) Jubin, R. T. A Modified Mathematical Model for Calculating Distribution Coefficients for $U(V I), P u(I V)$, and Nitric acid in the Uranyl Nitrate-Plutonium (IV) Nitrate-Nitric AcidWater/Tributyl Phosphate System; ORNL/TM-7217; Oak Ridge National Laboratory: Oak Ridge, 1980

(18) Tachimori, S. EXTRA.M: A Computer Code System for Analysis of the Purex Process with Mixer Settlers for Reprocessing; JAERI-1331; Japan Atomic Energy Research Institute: Tokyo, Japan, 1993.

(19) Tsubata, Y.; Asakura, T.; Morita, Y. Development of a Computer Code, PARC, for Simulation of Liquid-Liquid Extraction Process in Reprocessing; JAEA-Data/Code 2008-010; Japan Atomic Energy Agency: Tokyo, Japan, 2008.

(20) Chen, H.; Taylor, R. J.; Jobson, M.; Woodhead, D. A.; Masters, A. J. Development and Validation of a Flowsheet Simulation Model for Neptunium Extraction in an Advanced PUREX Process. Solvent Ext. Ion Exch. 2016, 34(4), 297-321.

(21) Chen, H.; Taylor, R. J.; Jobson, M.; Woodhead, D. A.; Boxall, C.; Masters, A. J.; Edwards, S. Simulation of Neptunium Extraction in an Advanced PUREX Process-Model Improvement. Solvent Ext. Ion Exch. 2017, 35(1), 1-18. 
(22) Petrich, G.; Z. Kolarik, K. The 1981 Purex Distribution Data Index; KfK3080; Kernforschungszentrum Karlsruhe GmbH: Karlsruhe, Germany, 1981

(23) Chapman, W. G.; Gubbins, K. E.; Jackson, G.; Radosz, M. SAFT: Equation of State Model for Associating Fluids. Fluid Phase Equilib.1989, 52, 31-38.

(24) Huang, S. H.; Radosz, M. Equation of State for Small, Large, Polydisperse, and Associating Molecules: Extension to Fluid Mixtures. Ind. Eng. Chem. Res. 1991, 30, 19942005.

(25) Gil-Villegas, A.; Galindo, A.; Whitehead, P. J.; Mills, S. J.; Jackson, G.; Burgess, A. N. Statistical Associating Fluid Theory for Chain Molecules with Attractive Potentials of Variable Range (SAFT-VR). J. Chem. Phys. 1997, 106, 4168-4186.

(26) Galindo, A.; Davies, L. A.; Gil-Villegas, A.; Jackson, G. The Thermodynamics of Mixtures and the Corresponding Mixing Rules in the SAFT-VR Approach for Potentials of Variable Range. Mol. Phys. 1998, 93(2), 241-252.

(27) Galindo, A.; Gil-Villegas, A.; Jackson, G.; Burgess, A. SAFT-VRE: Phase Behavior of Electrolyte Solutions with Satistical Associating Fluid Theory for Potentials of Variable Range. J. Phys. Chem. B 1999, 103(46), 10272-10281.

(28) Wei, Y. S.; Sadus, R. J. Equations of State for the Calculation of Fluid-Phase Equilibria. AIChE J. 2000, 46(1), 169-196.

(29) Gross, J.; Sadowski, G. Perturbed-Chain SAFT: An Equation of State Based on a Perturbation Theory for Chain Molecules. Ind. Eng. Chem. Res. 2001, 40, 1244-1260. 
(30) Eriksen, D. K.; Lazarou, G.; Galindo, A.; Jackson, G.; Adjiman, C. S.; Haslam, A. J. Development of Intermolecular Potential Models for Electrolyte Solutions Using an Electrolyte SAFT-VR Mie Equation of State. Mol. Phys. 2016, 114(18), 2724-2749.

(31) Dufal, S.; Papaioannou, V.; Sadeqzad, M.; Pogiatzis, T.; Chremos, A.; Adjiman, C. S.; Galindo, A. Prediction of Thermodynamic Properties and Phase Behavior of Fluids and Mixtures with the SAFT- $\gamma$ Mie Group-Contribution Equation of State. J. Chem. Eng. Data 2014, 59(10), 3272-3288.

(32) Gross, J.; Gabriele, S. Application of the Perturbed-chain SAFT Equation of State to Associating Systems. Ind. Eng. Chem. Res. 2002, 41, 5510-5515.

(33) Diamantonis, N. I.; Boulougour, G. C.; Mansoor, E.; Tsangaris, D. M.; Economou, I. G. Evaluation of Cubic, SAFT, and PC-SAFT Equations of State for the Vapor-Liquid Equilibrium Modeling of $\mathrm{CO}_{2}$ Mixtures with Other Gases. Ind. Eng. Chem. Res. 2013, 52, 3933-3942.

(34) Paricaud, P.; Tazi, L.; Borgard, J. M. Modeling the Phase Equilibria of the HIx Mixture Using the SAFT-VRE Equation of State: Binary Systems. Int. J. Hydrogen Energy 2010, 35, 978-991.

(35) Fukumoto, A.; Paricaud, P.; Dalmazzone, D.; Bouchafaa, W.; Ho, T. T.; Fürst, W. Modeling the Dissociation Conditions of Carbon Dioxide + TBAB, TBAC, TBAF, and TBPB Semiclathrate Hydrates. J. Chem. Eng. Data 2014, 59, 3193-3204.

(36) Schreckenberg, J. M. A.; Dufal, S.; Haslam, A.; Adjiman, C.; Jackson, G.; Galindo, A. Modelling of the Thermodynamic and Solvation Properties of Electrolyte Solutions with the 
Statistical Associating Fluid Theory for Potentials of Variable Range. Mol. Phys. 2014, 112(17), 2339-2364.

(37) Pelendritis, M. Nuclear Fuel Waster Extraction - Third Phase Revisited. PhD Thesis, The University of Manchester: Manchester, UK, 2014

(38) Khoshkbarchi, M. K. A Theoretically Improved Perturbation Model for Activity Coefficients of Amino Acids and Peptides in Aqueous Solutions. Ind. Eng. Chem. Res. 1998, $37,3052-3057$.

(39) Tillner-Roth, R.; Frined, D. G. A Helmholtz Free Energy Formulation of the Thermodynamic Properties of the Mixture \{Water+Ammonia\}. J. Phys. Chem. Ref. Data 1998, 27(1), 63-96.

(40) Rozen, A. M.; Andrutskii, L. G.; Vlasov, V. S. Improved Mathematical Models of Actinide Extraction by 30\% Solutions of the Tri-n-butylphosphate in Diluents. Atomnaya Energiya 1987, 62(4), 227-231.

(41) Chaiko, D. J.; Vandegrift, G. F. A Thermodynamic Model of Nitric Acid Extraction by Tri-n-butyl Phosphate. Nucl. Technol. 1988, 82(1), 52-59.

(42) Enokida, Y.; Yamamoto, I. Distribution Coefficient Correlations for Nitric Acid, U(VI) and $\mathrm{Pu}(\mathrm{IV})$ in Two-phase System with Aqueous Nitric Acid and 30\% Tri-n-Butylphosphate Solutions. J. Nuclear Sci. Technol. 1997, 34(7), 700-707. 
(43) Kolarik, Z.; Dressler, P. PUREX Process Related Distribution Data on Neptunium $(I V, V I)$. KfK-4667, Karlsruhe, Germany, January, 1990

(44) Birkett, J. E.; Carrott, M. J.; Crooks, G., Maher, C. J.,Fox, O. D., Jones, C. J.,Roube, C. V., Taylor, R. J., Woodhead, D. A. Control of Neptunium Routing During the Reprocessing of Spent Nuclear Fuel Using Purex. In Recent Advances in Actinide Science; Alverez, R.; Bryan, N.D.; May, I. Eds; Royal Society of Chemistry: Cambridge; 2006; pp. $641-643$.

(45) Lafitte, T; Papaioannou, V.; Dufal, S.; Pantelides, C. C. gSAFT: Advanced Physical Property Prediction for Process Modelling. In Proceedings of the 27th Europen Symposium on Computer Aided Process Engineering; Espuna, A.; Graells, M.; Puigjaner, L. Eds.; Elsevier B.V.: Barcelona, 2017; pp. 1003-1008

(46) Clark, G. N. I.; Haslam, A. J.; Galindo, A.; Jackson, G. Developing Optimal Wertheim-like Models of Water for Use in Statistical Associating Fluid Theory (SAFT) and Related Approaches. Mol. Phys. 2006, 104(22-24), 3561-3581.

(47) Botts, J. L.; Raridon, R. J.; Costanzo, D. A. Density, Acidity, and Conductivity Measurements of Uranyl Nitrate/Nitric Acid Solutions; ORNL/TM-6491; Oak Ridge National Laboratory: Oak Ridge, 1978

(48) Cauchetier, P. Determination de la Relation Liant la Masse Volumique de Solutions Aqueuses a Leur Concentration en Acide Nitrique, Uranium et Plutonium et a la Temperature; CEA-R-5322; Centre d'Etudes Nucleaires de Fontenay aux Roses: Gif-surYvette Cedex, France, 1985 
(49) Boualia, A.; Mellah, A.; Silem, A. Correlations Empiriques de la Densite du Nitrate d'Uranyle dans des Solutions d'Acide Nitrique 0-1 M. Hydrometallurgy 1989, 22, 223-230.

(50) Yu, Y.; Bao, T.; Gao, G.; Li, Y. Densities and Apparent Molar Volumes for Aqueous Solutions of $\mathrm{HNO}_{3}-\mathrm{UO}_{2}\left(\mathrm{NO}_{3}\right)_{2}$ at 298.15 K. J. Radioanal. Nucl. Chem. 1999, 241(2), $373-$ 377.

(51) Sakurai, S.; Tachimori, S. Modified Density Equation for Aqueous Solutions with Plutonium(IV), Uranium(VI) and Nitric Acid; JAERI-M 88-127; Japan Atomic Energy Research Inistitute: Tokai-mura, Japan, 1988

(52) Process Systems Enterprise, gPROMS Model Builder (C), Available at: https://www.psenterprise.com/products/gproms/modelbuilder

\section{TOC graphic}

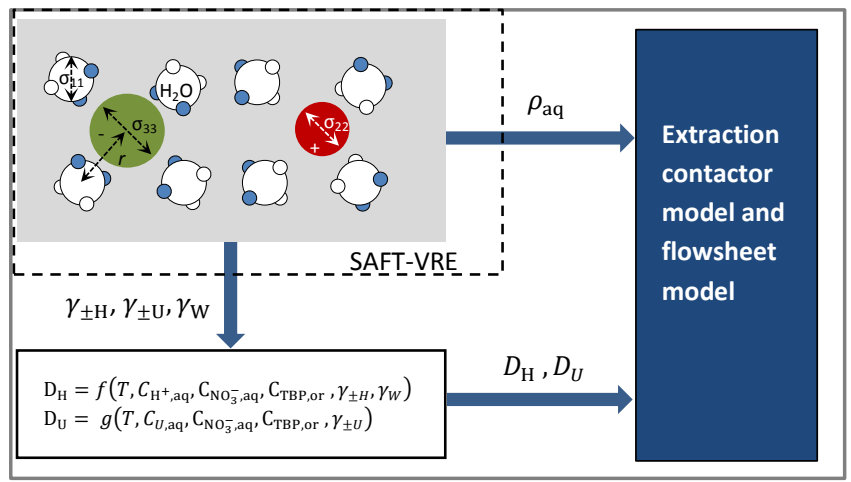

